\title{
Whistleblowing in the Wind Towards a Socially Situated Research Agenda: A Response to Recent Commentaries
}

\author{
Russell Mannion ${ }^{1 *}$, Huw T.O. Davies ${ }^{2}$

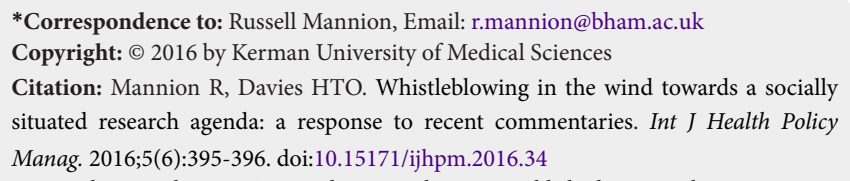

$\mathrm{W}$ e would like to thank all those who responded to our editorial: 'Cultures of Silence, Cultures of Voice: Whistleblowing in Healthcare Organisations.' Each commentary critically engaged with the ideas we set out, offering some affirmation but also taking the discussions in new directions with important implications for the development of the future research agenda in this area.

Charles Frederick Alford has produced some of the seminal work on whistleblowing. In his commentary, he argues that modern (healthcare) organisations seek to promote and instil institutional loyalty among members via rituals and other culture management strategies. This creates tensions as employees need to reconcile being citizens of the organisation with being citizens in a wider sense: as members of the public, as patients and as taxpayers. ${ }^{2}$ Alford offers no easy solutions to these tensions, but notes that our societies are fortunate that there are people who are unable not to speak out, rightly noting that much organisational wrong-doing is only visible from the inside.

John Blenkinsopp and Nicholas Snowden ${ }^{3}$ articulate the need to nurture leadership cultures in healthcare organisations that promote the open identification and resolution of problems with regard to poor quality care, rather than cultures and leadership that implicitly encourage suppression and denial. In this sense, they argue that healthcare leaders at all levels of the health system need to reframe whistleblowing and open reporting as something that is positive and valuable, something that can become embedded within routine organisational practices. If successful, we could argue that such reframing usefully moves us away from traditional notions of whistleblowing as aberrant practice.

Sonja Cleary and Kerrie Doyle ${ }^{4}$ argue that we need a better understanding as to why some healthcare managers display not only the courage to hear negative feedback and then take appropriate action, but also the courage to refrain from inappropriate action such as scapegoating those voicing bad news. They highlight the need for research to explore the variables that determine courage on the part of organisational recipients of bad news. In a sense such arguments chime with those of Blenkinsopp and Snowden (and us) in seeking greater sensitivity and responsiveness to unwelcome messages within

\section{organisations.}

Paula Hyde ${ }^{5}$ argues that what is deemed to constitute poor quality care and unsafe practice is shaped in part by broader institutional forces affecting healthcare organisations. For example, as austerity measures are put in place, eligibility criteria for certain services may be redefined to limit demand. It is unlikely that patients' interests are best served by these restrictions, but when do such changes become unacceptable? And when should the alarm be raised? And with whom? Hyde argues that for a fuller understanding of whistleblowing we also need to understand how well-meaning workers might come to commit harm on behalf of the organisation, and such notions speak to our own observations about the ambiguity of whistleblowers and the actions about which they speak. ${ }^{1}$ Continuing a recurrent theme across the commentaries, Aled

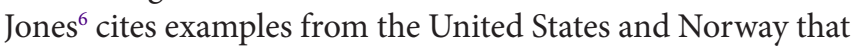
suggest that workplace environments that value employee whistleblowing and voice are both possible and effective. The examples provided demonstrate a preoccupation with constantly monitoring systems of reporting and responding, ensuring that these are focused on learning and system improvement. Jones also highlights that developing and maintaining a pro-learning workplace culture cannot be achieved by merely bolting-on a reporting system that is then left to run unattended and unmonitored. ${ }^{6}$ Ongoing attention to such systems remains a neglected area of both practice and research.

In bringing some conceptual clarity to several intertwined issues, Robert MacDougall ${ }^{7}$ argues that the term whistleblowing should be reserved for those cases that involve going outside the organization: employees who consider performing this kind of reporting are in a morally specific situation through facing a conflict of duties. In this sense, whistleblowers have to choose between failing in a duty to the wider public and failing in a duty to their employee - and in becoming whistleblowers they chose to fail in their duty to their employer. This is indeed a moral tension as MacDougall highlights that whistleblowing can cause tremendous damage to organisations, even when the allegations turn out to be untrue (however, that is adjudged).

In tandem with some of the other commentators, Edgar Schien $^{8}$ also argues that instead of worrying about the pros and cons of whistleblowing one should consider the more general problem of the failure of upward communication within organisations around safety and that the focus should shift to how managers can encourage employees to openly report problems. He introduces the concepts of 'practical drift' and 'adaptive moves' as necessary for systemic safety

Full list of authors' affiliations is available at the end of the article. 
to be understood and better handled. Schein also argues that the most important adaptive move that can be taken by leaders is to reduce professional distance and 'personalize' their relationships with employees: getting to know them as individuals rather than as occupants of technical or professional roles. So here again we see arguments for a reintegration of the goals served by whistleblowing into better organisational functioning.

Finally, for Justin Waring ${ }^{9}$ the decision to speak up is located within a more complex set of social relationships and norms. Waring draws on the dramaturgical metaphor introduced by Ervin Goffman, noting that backstage cultures have the potential to hoard and conceal knowledge about performance issues that might better be addressed through working in the front-stage or indeed more directly with the audience. He argues that the patients and the public should have greater exposure to - and influence upon - the mechanics of the healthcare 'performance'. Such a direction of travel is of course not without risk and will itself require careful planning and management.

Taken together the arguments emerging through the various commentaries highlight the need for a new socially situated research agenda, not just of whistleblowing as aberrant activity, but of the full range of organisationally-embedded communications, sense-making and judgement-forming. While some form of whistleblowing - and the social, legal and structural arrangements in support of it - may always be necessary, a better understanding of its dynamics may paradoxically enable a diminution of its prominence.

Ethical issues

Not applicable.

\section{Competing interests}

Authors declare that they have no competing interests.

Authors' contributions

Both authors contributed equally to the writing of this paper.

Authors' affiliations

${ }^{1}$ Health Services Management Center, University of Birmingham, Birmingham, UK. ${ }^{2}$ Social Dimensions of Health Institute, Universities of Dundee and St Andrews, Fife, UK.
References

1. Mannion $\mathrm{R}$, Davies $\mathrm{H}$, Cultures of silence and cultures of voice: the role of whistleblowing in healthcare organisations. Int J Health Policy Manag. 2015;4(8):503-505. doi:10.15171/ijhpm.2015.120

2. Alford CF. What makes whistleblowers so threatening? Comment on "Cultures of silence and cultures of voice: the role of whistleblowing in healthcare organisations." Int J Health Policy Manag. 2016;5(1):71-73. doi:10.15171/ijhpm.2015.183

3. Blenkinsopp J, Snowden N. What About Leadership? Comment on "Cultures of silence and cultures of voice: the role of whistleblowing in healthcare organisations." Int J Health Policy Manag. 2016;5(2):125-127. doi:10.15171/ijhpm.2015.193

4. Cleary SR, Doyle KE. Whistleblowing need not occur if internal voices are heard: from deaf effect to hearer courage: Comment on "Cultures of silence and cultures of voice: the role of whistleblowing in healthcare organisations." Int $J$ Health Policy Manag. 2016;5(1):59-61. doi:10.15171/ijhpm.2015.177

5. Hyde PA. A wicked problem? Whistleblowing in healthcare organisations: Comment on "Cultures of silence and cultures of voice: the role of whistleblowing in healthcare organisations." Int J Health Policy Manag. 2016;5(4):267-269. doi:10.15171/ ijhpm.2016.01

6. Jones $A$. The role of employee whistleblowing and raising concerns in an organizational learning culture - elusive and laudable? Comment on "Cultures of silence and cultures of voice: the role of whistleblowing in healthcare organisations." Int J Health Policy Manag. 2016;5(1):67-69. doi:10.15171/ ijhpm.2015.182

7. MacDougall DR. Whistleblowing: don't encourage it, prevent it: Comment on "Cultures of silence and cultures of voice: the role of whistleblowing in healthcare organisations." Int $\mathrm{J}$ Health Policy Manag. 2016;5(3):189-191. doi:10.15171/ijhpm.2015.190

8. Schein EH. Whistle blowing: a message to leaders and managers: Comment on "Cultures of Silence and Cultures of Voice: The Role of Whistleblowing in Healthcare Organisations." Int J Health Policy Manag. 2016;5(4):265-266. doi:10.15171/ ijhpm.2015.207

9. Waring J. When whistle-blowers become the story: the problem of the 'third victim': Comment on "Cultures of silence and cultures of voice: the role of whistleblowing in healthcare organisations." Int J Health Policy Manag. 2016;5(2):133-135. doi:10.15171/ ijhpm.2015.197 